This item was submitted to Loughborough's Institutional Repository (https://dspace.lboro.ac.uk/) by the author and is made available under the following Creative Commons Licence conditions.

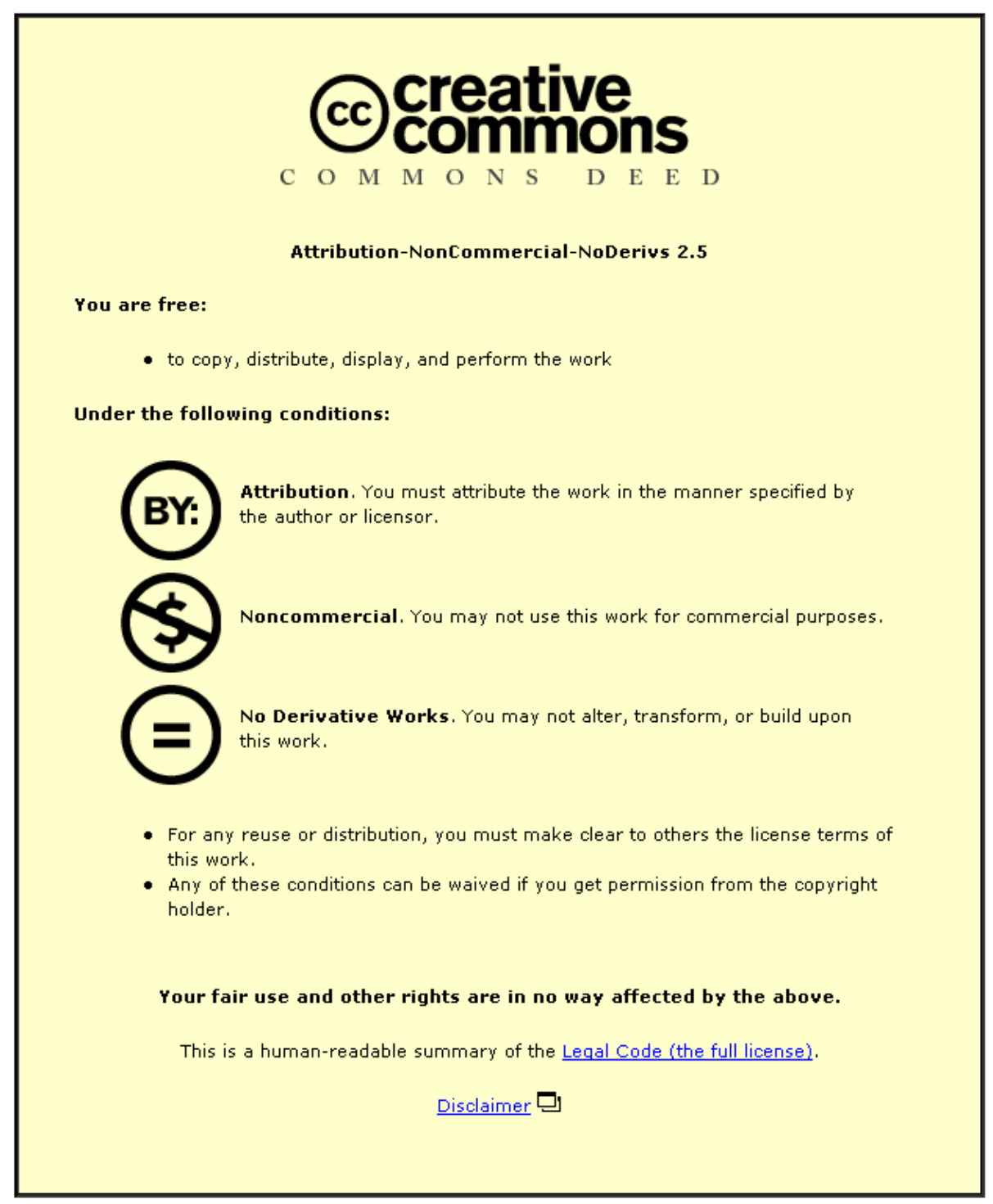

For the full text of this licence, please go to: http://creativecommons.org/licenses/by-nc-nd/2.5/ 


\title{
Performance evaluation of natural ventilation strategies for hospital wards - A case study of Great Ormond Street Hospital
}

\author{
Adamu, Z.A. ${ }^{1^{*}}$, Price A.D.F. ${ }^{*}$ and Cook, M.J. \\ 1..a.adamu@lboro.ac.uk \\ ${ }^{1}$ Tel: +44 755231 2811; Fax: +44 1509223981 \\ * School of Civil and Building Engineering, Loughborough University, Loughborough, LE11 3TU, \\ United Kingdom
}

\begin{abstract}
Natural ventilation is attractive due its potential to lower energy consumed by healthcare environments but maintaining steady/adequate airflow rates and thermal comfort is challenging in temperate countries. Although many contemporary hospitals use traditional windows for natural ventilation, there are alternative strategies that are largely under-utilised probably due to lack knowledge of their ventilation performances. Each alternative has design implications and airflow characteristics - both of which affect thermal comfort and heating energy. This study evaluates the performance of buoyancy-driven airflows through four selected natural ventilation strategies suitable for single-bed hospital wards. These strategies are: single window opening, same side dual-opening, inlet and stack as well as ceiling-based natural ventilation (CBNV), a new concept. These strategies have been explored via dynamic thermal simulation and computational fluid dynamics, using a new ward of the Great Ormond Street Hospital (GOSH) London as a case study. Results reveal that 25\% trickle ventilation opening fraction is required to achieve required airflow rates and acceptable thermal comfort in winter, and with exception of window-based design, other strategies minimise summer overheating to different extents. The CBNV concept uniquely shields fresh air and delivers it to isolated parts of wards or directly over patients (i.e. personalisation). This provides higher air quality at such locations and creates mixing which aids comfort and dilution. The findings demonstrate how quantitative data from simulations can be used by designers to meet qualitative or sensory design objectives like airflow direction and thermal comfort with respect to the energy consumed in space and time.
\end{abstract}

Keywords: buoyancy-driven airflow, hospital ward, thermal comfort, energy consumption, dynamic thermal modelling, ceiling-based natural ventilation.

\subsection{Introduction}

\subsection{Natural ventilation in hospitals}

A major advantage of natural ventilation in healthcare facilities is the significant ventilation rates (18 $24 \mathrm{ACH}$ ) that can be achieved for wards which can be bonus if airborne infection is a risk [1]. In their study of a Hong Kong hospital, they [1] showed that up to $69 \mathrm{ACH}$ was possible given the right environmental conditions and that when carefully integrated with exhaust fans, such hybrid systems can eliminate the unreliability of driving forces like wind or problems associated with pressure breakdown due to activities like opening of doors. The apparent need in countries like the UK, to refurbish existing stock of hospital buildings with low-energy ventilation solutions in a manner that permits their resilience to a warming climate makes natural ventilation a logical alternative [2]. Studies on achieving low energy hospital ventilation in the UK [3] have therefore been undertaken to demonstrate how shaft and stack-based strategies as used in advanced natural ventilation [4] could be considered for wide-scale adoption -including for refurbishing of existing hospital stock. ANV has benefits of relying not on winds but on buoyancy forces [4]. Other stack-based approaches that could have potential for ventilation of hospital facilities include solar chimneys [5] although there is no strong evidence of its application in healthcare. These alternative ventilation strategies are not yet in the mainstream as design options but they have lower carbon and operational costs compared to 
mechanical ventilation $[4,5]$. The choice of a natural ventilation strategy for refurbishment will be constrained by the logistic of constant usage [6] and patient susceptibility to noise [2]. One strategy that has not featured as a refurbishment option in contemporary literature is same side dual-opening, which though may be restricted to low-rise facilities [7] could be better than existing single (window) openings.

As for room air distribution, displacement ventilation which is a feature of buoyancy-driven natural ventilation has advantages over mixing ventilation in healthcare settings as long as bio-aerosols are not of concern in a particular space earlier shown by Beggs, et al. 2008 [8] and more recently in Li, et al. (2011) [9]. In particular, displacement is not recommended for ward ventilation whether in single or multi-patient spaces since it is adjudged as incapable of protecting healthcare workers, patients or their visitors [11]. This deduction brings with it some implications on the displacement strategies already in use or emerging/recommended for hospital wards, such the buoyancy-driven ANV [3]. However, a new approach to buoyancy-induced natural ventilation which is capable of providing not only mixing but personalised delivery of fresh air over patients has been demonstrated [10] through the use of ceiling mounted supply ducts with exhaust air escaping via stacks. These findings and their implications hence make it necessary to evaluate the performance of selected (and fundamentally different) natural ventilation strategies in terms of their airflow rates/room air distribution patterns, thermal comfort as well as energy potential.

There are currently many different modelling approaches used in predicting building ventilation including analytical models, empirical models, multizone models, zonal models, models, experimental models and computational fluid dynamics (CFD) models [11]. The use of CFD in particular has risen steadily since 2002, especially within the research community, where it has become a major tool for airflow investigations. The wide applicability, acceptability of CFD as a ventilation modelling tool is however tied to its concurrent use with theoretical and experimental models as verification and validation of available codes become increasingly important [12]. This study intends to use (zonal) dynamic thermal model (DTM) as well as CFD modelling as methods of airflow investigation.

The UK's Department of Health technical memorandum (HTM 03-01) allows natural ventilation as an acceptable method of ventilation of hospital spaces but is silent on how this can be achieved, especially with respect to the six air changes per hour (ACH) [13] which was specified as minimum rate for wards. This rate has been suspected as being 'arbitrary' due to lack of evidence-based performance studies [14,15]. The World Health Organisation (WHO) on the other hand has documented a specific guideline for natural ventilation of hospitals, in which it strongly recommends the rate of $60 \mathrm{l} / \mathrm{s} /$ patient [16]. However, there is no specific guidance on how this rate can be accomplished with acceptable climatic conditions or for that matter, what the rates should be during winter when trickle ventilation needs to be maintained. It has also been established that for hospital wards, airflow rates need to be deployed with engineered patterns as well as directions of airflow for effective ventilation of hospital wards [17]. Besides, achieving this rate steadily with natural ventilation is challenging because, unlike mechanical ventilation, the driving forces (i.e. wind and buoyancy) tend to fluctuate depending on climatic factors as well as occupancy and miscellaneous internal heat loads.

There is, therefore, a need for evidence-based investigations to support these provisions for the benefit of practitioners. In this regard, dynamic thermal simulation (DTS) and computational fluid dynamics (CFD) modelling techniques can simultaneously provide annual bulk airflow and detail room air distribution characteristics, respectively.

\subsection{Objectives and justifications}

The primary aim of this work is to provide a comparative evaluation of the ventilation, thermal comfort and energy performances that can be expected from four selected natural ventilation strategies applicable to hospital wards. The natural ventilation will focus on bouyancy-driven flows only, which 
can be valuable for facilities located in urban locations where wind forces are unreliable or minimal. The study specifically intends to: (a) determine and evaluate airflow and energy performance of different configurations of natural ventilation openings with respect to their sizes and locations; (b) establish if and how regular, as well as trickle ventilation rates, can be achieved with buoyancy induced airflows keeping the WHO's natural ventilation requirement of $60 \mathrm{l} / \mathrm{s} /$ patient in perspective; (c) present a concept called ceiling-based natural ventilation and its benefits regarding airflow and energy and finally (d) to demonstrate benefits of a two-pronged approach for studying the airflow, comfort and energy performance of natural ventilation using dynamic thermal simulation and computational fluid dynamics. The research findings should empower designers with sufficient knowledge needed to make informed decisions with respect to low-energy hospital ventilation, especially considering that over $40 \%$ of a typical UK hospital's energy goes into space conditioning [18].

\subsection{The natural ventilation concepts}

The Great Ormond Street Hospital (GOSH) has a single occupant wards one of which was adopted as a case study to achieve the stated objectives. The dimensions of the GOSH ward are $3.78 \times 6.23 \mathrm{~m}$ with ceiling height of $3.5 \mathrm{~m}$, giving a floor area of $23.55 \mathrm{~m}^{2}$ and a volume of $82.42 \mathrm{~m}^{3}$. The existing window is $1.65 \mathrm{~m}$ wide and $0.5 \mathrm{~m}$ high and is situated $1.9 \mathrm{~m}$ above a fixed glazing of same width. The plan and section of the GOSH ward are shown in Fig. 1.
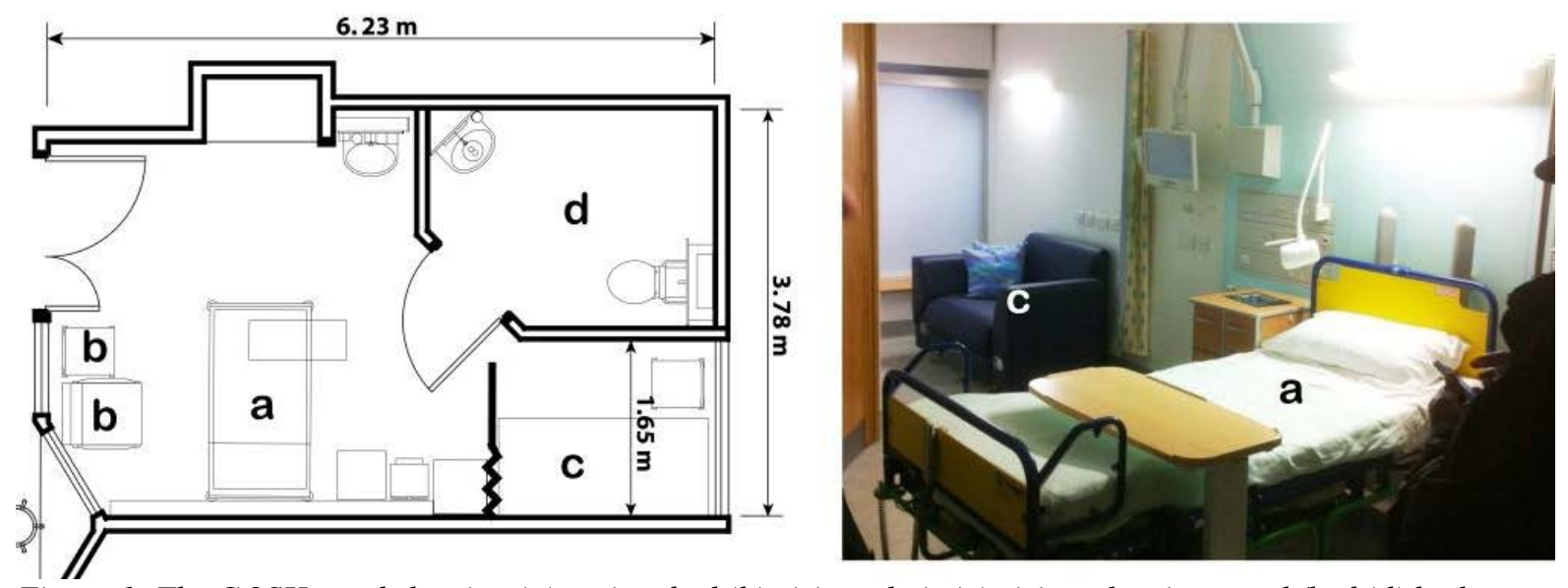

Figure 1: The GOSH ward showing (a) patient bed (b) visitor chair (c) visitor sleeping couch/bed (d) bathroom

The following subsections describe the various strategies investigated with the above ward design. Although there is an en-suite bathroom which has an extract fan that works occasionally, the operation of this fan is not modelled in terms of its impact on airflow or energy. This is because the goal of this study is to demonstrate the feasibility of buoyancy driven flows into the main ward space only.

\subsubsection{The (as-built) single window concept}

Case 1 model, which serves as the base case for this investigation, was derived directly from the asbuilt design of the GOSH ward with minor modifications. It utilises a $1.9 \mathrm{~m}$ high-level top-hung window on the exterior wall just above a fixed glazed area (Fig. 2a). Although CIBSE [19] provides guidance on sizing single vent buoyancy driven openings using Eq. 1, there was no evidence that this model was applied in sizing the window of the existing ward. It is presented here nevertheless for the benefit of designers:

$A=Q / C_{d} \sqrt{ }\left(T_{\text {int }}+273\right) /\left(T_{\text {int }}-T_{\text {ext }}\right) g H$ 
where $A$ = area of opening $\left(\mathrm{m}^{2}\right) ; Q=$ required ventilation rate $\left(\mathrm{m}^{3} / \mathrm{s}\right) ; C_{d}=$ discharge coefficient; $T_{\text {int }}=$ internal temperature (K); $T_{\text {ext }}=$ external temperature $(\mathrm{K}) ; g=$ gravitational force per unit mass $\left(\mathrm{m} . \mathrm{s}^{-2}\right)$ and $H=$ height of opening. In the application of this model for single vent, $\mathrm{C}_{\mathrm{d}}$ typically takes a value of 0.25 [19]. In Fig. 2a, the window opening is shown in shaded black, above the fixed glazed area.

\subsection{Same side dual-opening}

Case 2 of this study was conceived as two openings of same area, separated vertically. The areas of inlets and outlets for dual opening vents were also obtained from Eq. 1, from [19]. In this instance, the value of $C_{d}$ is typically 0.6 and $H$ becomes the height between the two openings. It is evident from Eqn. 1 that the required flow rate, $Q$, the temperature differential $\Delta \mathrm{T}$ i.e. $T_{i n t}-T_{e x t}$ and the vertical distance between the two openings $H$, will all affect the size of opening, $A$. In this study, $C_{d}$ and $g$ were taken as 0.6 and $9.81 \mathrm{~m} / \mathrm{s}^{2}$ respectively, while $\Delta \mathrm{T}$ was assumed to be 1 . Computed area of opening was found to be $0.78 \mathrm{~m}^{2}$ when the vertical distance, $H$, between the openings is maximised to $2.5 \mathrm{~m}$, measured from their centres. Due to width of existing glazed area $(1.65 \mathrm{~m})$ being a constraint (see Fig. 1) in determining width of opening, the dimensional sizes applied in the model were therefore $0.47 \times 1.65 \mathrm{~m}$. The schematic of this case is represented in Fig. 2b showing the fixed glazing between the two openings.

\subsubsection{Inlet and stack concept}

Case 3 concept comprises a low level inlet and exhaust stack and can be regarded as a type of advanced natural ventilation, (ANV) as presented in [4]. In this study, the inlet and stack strategy is analogous to edge-in, edge-out ANV strategy because both openings are on the external wall. The stack sizes were based on the estimation techniques given by Lomas and Ji [15] where the free opening area is assumed to be a fraction, $F$, of the gross floor area. Typical values of $F$ range from 0.5 to $1.5 \%$ and the computed area should not be less than the area of the supply inlets so that flow is not restricted. Furthermore, the authors indicated that even though the value of $F$ may appear small, it is the length of shaft which then becomes a primary determining factor in the stack performance. The process used to derive the cross-sectional area of a stack (As) when a given space of width $W$, has a depth $n . W$ (where $\mathrm{n}$ is the aspect ratio or depth/width) is given by [15] as shown in Eq. 2.

$A s=F n W^{2}\left(m^{2}\right)$

In this study, $F$ is assumed to be $1.5 \%$ of floor area (or 0.015 ) and $n=1.65$, and $W=3.78$. As was then computed to be $0.35 \mathrm{~m}^{2}$. The exhaust stacks were then translated into dimensional size of $0.5 \mathrm{x} 0.7 \mathrm{~m}$; and for simplicity, the stack height was assumed to be equal to floor height (i.e. $3.5 \mathrm{~m}$ ). The area of stack therefore determined the size of air inlets, which for Case 3 was a low level inlet sized at $0.21 \mathrm{x}$ $1.65 \mathrm{~m}$. The conceptual design of Case 3 is shown in Fig. 2c. 


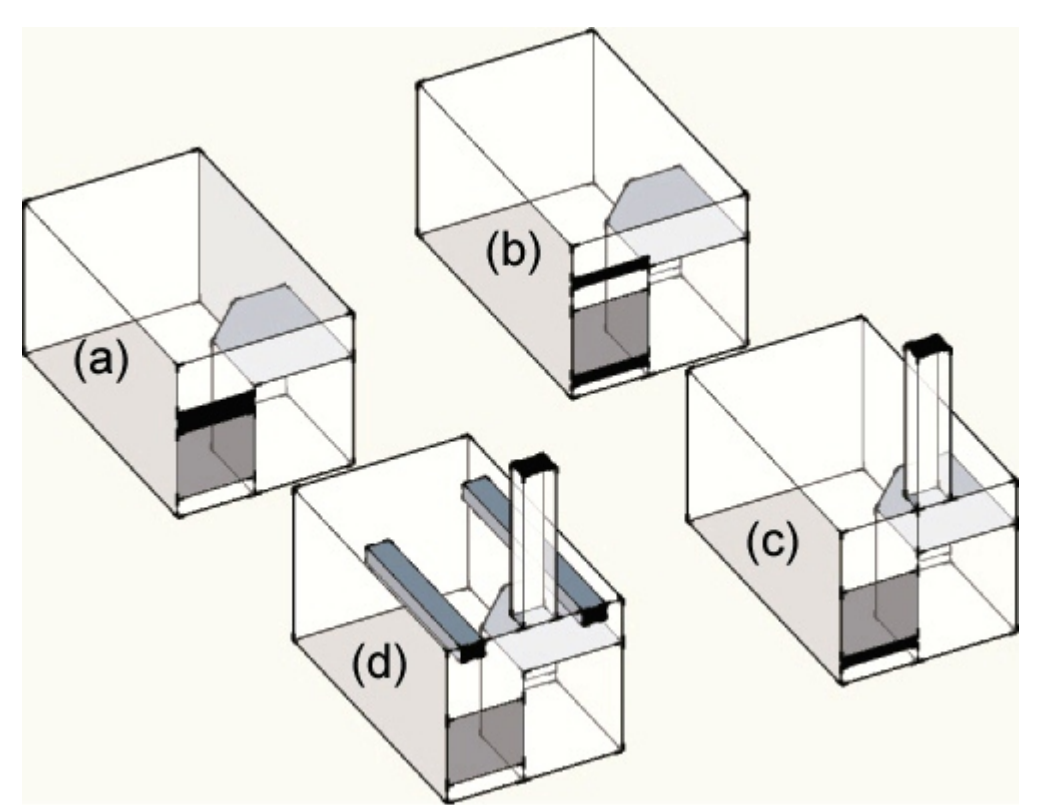

Figure 2: Four strategies with openings shown in solid black for (a) single window (b) dual-opening (c) inlet and stack (d) ceiling-based strategy

\subsubsection{Ceiling-based natural ventilation concept}

Case 4, which is the ceiling-based natural ventilation strategy, is based on conceptual principles that depend on two main factors. The first is density of cooler air falling into the warmer surrounding; while the second is the behaviour of non-isothermal jet including its flow velocity in a duct as well as drop distance of the air [20]. Assuming that the indoor air is at a higher temperature than outdoor air, the denser cooler would travel along the duct and then drop down before rising again. Subsequently, the air gets heated due to convective and radiated heat from miscellaneous internal sources (lighting, people and equipment) before it escapes into the stack whose pressure boundary is much higher than the duct inlet (Fig. 2d). The use of ceiling-based ducts to convey fresh air under buoyancy has already been demonstrated in previous work by Adamu et al., [12] as a novel way of achieving natural personalised ventilation (NPV). The NPV was shown to be natural ventilation equivalent of mechanised PV systems as defined in [21], however, as conceived for this study, the NPV concept can be applied for isolated spaces even if personalised delivery of air to patients is not the goal. Ceilingbased natural ventilation is, therefore, a superior nomenclature which encompasses the essential concept and in this study because one duct serves NPV purposes while the other provides supplementary fresh air to isolated spaces. The height of the stack relative to the duct inlets determines the neutral pressure line (NPL) which in addition to temperature differential determines the pressure difference needed to induce buoyant flow of air. The openings in Case 4 had same size as Case 3 $\left(0.35 \mathrm{~m}^{2}\right)$ which was shared equally by the two ducts giving each an area of $0.175 \mathrm{~m}^{2}$. This translated into $0.5 \times 0.35 \mathrm{~m}$ in absolute dimensions. Stack size in this case remained similar to Case 3 in crosssectional area, height and location.

\subsection{Materials and methods \\ 2.1 Performance metrics}

Three categories of performance metrics are used in this study. For ventilation, the 6 ACH of HTM 03-01 [13] and the $60 \mathrm{l} / \mathrm{s} /$ patient of the WHO's guideline on natural ventilation for hospitals [16] are used in addition to EN ISO 7730 recommendation [22] of $2 \mathrm{l} / \mathrm{s} / \mathrm{m}^{2}$ dilution rates for Class I buildings, which for the given floor area of $23.55 \mathrm{~m}^{2}$, equates into $\approx 47 \mathrm{l} / \mathrm{s}$. For thermal comfort, the predicted mean vote (PMV) ranges specified for Class I buildings under the EN ISO 7730 standard [22] is 
applied in addition to ISO's PMV and PPD indices [23] by cross-referencing these metrics with two heat setpoints used in the DTS simulation (i.e. 18 and $25^{\circ} \mathrm{C}$ ). The PMV ranges for this Class in [22] are defined as $-0.2<\mathrm{PMV}<+0.2$. For energy performance, the CIBSE energy benchmarks for Category 20 buildings (hospitals) of $90 \mathrm{~kW} \cdot \mathrm{h} / \mathrm{m}^{2}$ (electricity typical) and $420 \mathrm{~kW} \cdot \mathrm{h} / \mathrm{m}^{2}$ (fossil-thermal) are used with floor areas according to RICS gross internal area [24]. Hence, given a total floor area of $23.55 \mathrm{~m}^{2}$, (for the selected ward) each strategy has to aim for 2.12MWh if electricity is to be used or 9.89MWh if fossil-thermal source of energy is to be used.

\subsection{Base case and general assumptions}

For the CFD input, the chamfered edges of the bathroom (Fig. 1) were neglected due to software constraints. The mechanical extract operating in the bathroom was also omitted as the study aims at evaluating buoyancy-driven flows only. However, openings were made in the bathroom to allow air move in (low-level inlet) and out (high-level outlet); but only for Cases 2, 3 and 4. Three occupants were considered: a lying (covered) patient emitting 50W; a standing healthcare worker (HCW) and a sitting visitor, both emitting 90W each. Lighting produced 70W and, assuming it was made of fluorescent lamps enclosed in prismatic luminaires [25], the convection-to-radiation ratio of 20:80 becomes applicable. Hence, two luminaires emitted $7 \mathrm{~W}$ each while the floor radiated 56W. For the CBNV, due to the observed expected throw of cooler incoming jet of air [26, 20and12], the first duct over the patient had its canopy shortened backward (using engineering judgement) by $0.3 \mathrm{~m}$ from the assumed centre of the patient. This offset was expected to enable the jet of air to drop directly over the patient in the longitudinal direction of airflow. The second duct had its canopy extended $0.6 \mathrm{~m}$ further along the longitudinal direction creating a displacement of $0.9 \mathrm{~m}$ between the two CBNV duct supply points. An absolute floor-to-ceiling height of $3.5 \mathrm{~m}$ was used in all cases.

\section{$2.2 \quad$ Dynamic thermal simulation model}

DTS investigation was performed using IES [27]. With the exception of external wall, other surfaces were assumed to be adiabatic, similar to the conditions to be applied to the CFD models. The external wall construction was made of two plies of $100 \mathrm{~mm}$ brickwork and medium concrete, sandwiching $58.5 \mathrm{~mm}$ Styrofoam insulation, and finished with $15 \mathrm{~mm}$ gypsum plaster for a combined U-value of $0.35 \mathrm{~W} / \mathrm{m}^{2} \mathrm{~K}$. The intermittent occupancy had three people at peak times accounting for a total of 230W. Equipment and lighting contributed $75 \mathrm{~W}$ and $70 \mathrm{~W}$ respectively, with the former scheduled to be off from $10: 00 \mathrm{pm}$ to $06: 00 \mathrm{pm}$ daily. Two heat setpoints $\left(18^{\circ} \mathrm{C}\right.$ and the second at $\left.20^{\circ} \mathrm{C}\right)$ were considered while no cooling was considered even in summer. The air inlets and outlets were modelled at different opening factions but, for this study, 25\% opening fraction for winter months as well as $60 \%$ and $100 \%$ for summer period are reported. For winter, the goal was to assess opening fractions for adequate trickle ventilation (with respect to occupant comfort and heating energy) for all four strategies, whereas for summer the objective was to measure comfort and potential for overheating with openings fractions at $60 \%$ and $100 \%$.

\section{$2.3 \quad$ CFD model}

CFD modelling was performed using a commercial package PHOENICS [28]. With the exception of fixed glazing, all other surfaces were assumed to be adiabatic. After a series of pilot simulations to establish sufficient mesh, each case model comprised 45,000 cells (a grid of 30x50x30 cells) although in Case 3 and 4, the z-axis grid was increased to 60 cells to account for the stacks within the computational domain. The Boussinesq buoyancy approximation was applied to the standard RNG k- $\varepsilon$ turbulence model of Yakhot and Orszag, [29]. Satisfactory convergence was achieved using criteria of $0.1 \%$ error and this was attained after 5,000 iterations for Case 1 and 2; and after 6,000 and 7,000 iterations for Cases 3 and 4 respectively.

\subsection{Results and discussions}

The results from both DTS and CFD investigations are discussed below under airflow, comfort and energy sub-headings. 


\subsection{Airflow rates}

Using January as a sample winter month, all cases exhibit marked differences in airflow regimes as shown in Fig. 3. The monthly flow patterns via each strategy is shown in Fig. 3a, while minimum, maximum and mean airflow rates regime for each case is shown in Fig. $3 b$.

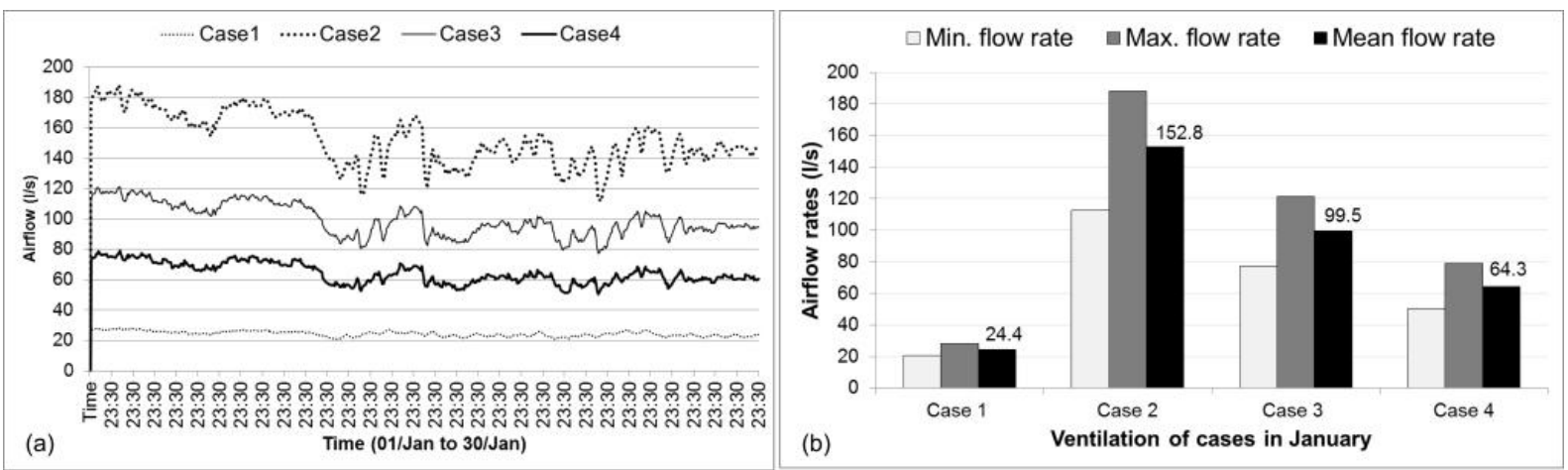

Figure 3: Airflow via 25\% opening in January showing (a) monthly flows and (b) minimum, maximum and mean flow rates

To rank their performances in airflow capacity, Case 1 produces the least flow rates, followed by Cases 4, 3 and Case 2. While it is proper to evaluate these flow rates with respect to either HTM 03-01 [13] or WHO's $60 \mathrm{l} / \mathrm{s} /$ patient [16], this ought to be done against backdrop of draught potential in January. In this regard, Case 2 presents the highest risk of draught, followed by Cases 3, 4 and 1.

The month of July was used for assessing the airflow rates in summer period (Fig. 4) when openings are either fully open at $100 \%$ or constricted to $60 \%$ of their maximum size. The observed pattern of airflow performance mimics the winter (January) situation where in increasing order, their performances are ranked: Case 1, Case 4, Case 3 and Case 2. Figure 4 shows the difference between airflow through openings at $100 \%$ and $60 \%$ fractions in which Case 2 performs better in both instances. Again, airflow rates into Case 1 are seen to fall significantly below those of other cases as observed from mean values for the month.

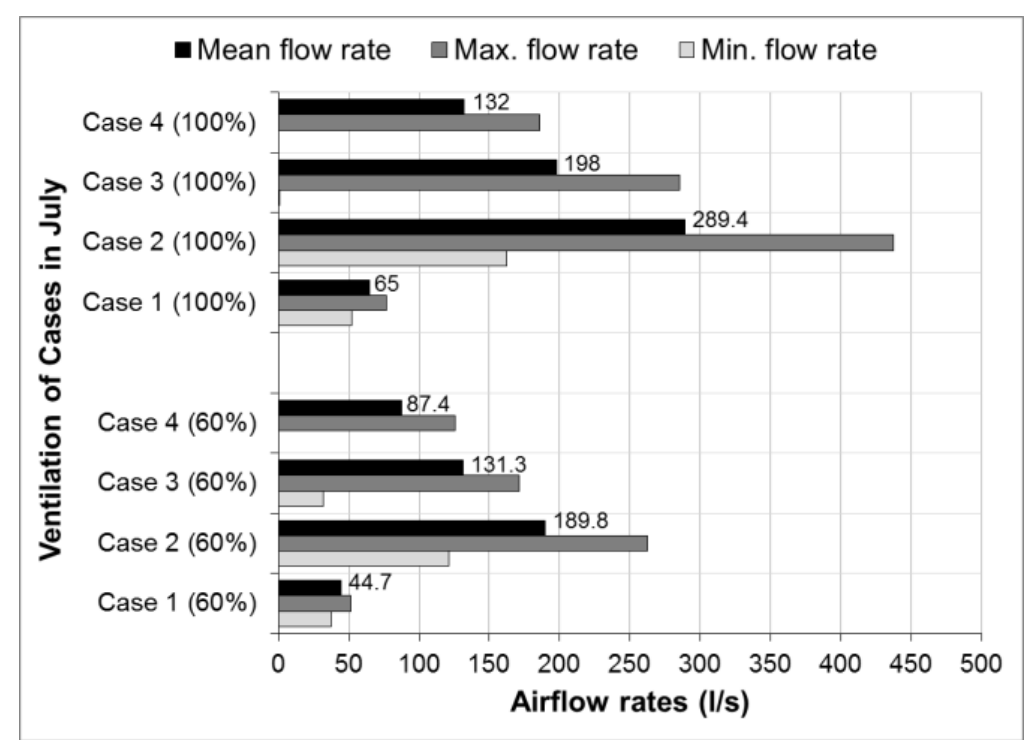

Figure 4: Airflow rates for all cases in July through 100\% and 60\% opening fraction 
Table 1 is a summary of how each strategy has performed using recommendations of HTM 03-01, the WHO and EN ISO 7730.

Table 1: Performance evaluation of mean airflow rates

\begin{tabular}{|c|c|c|c|c|c|}
\hline & & Case1 & Case2 & Case3 & Case4 \\
\hline \multirow{3}{*}{ 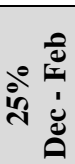 } & Mean flow rate $(\mathrm{l} / \mathrm{s})$ & 23.77 & 142.50 & 93.10 & 60.30 \\
\hline & Meets CIBSE's 20 l/s? & Yes & Yes & Yes & Yes \\
\hline & Meets WHO’s $60 \mathrm{l} / \mathrm{s} /$ patient & $\mathrm{No}$ & Yes & Yes & Yes \\
\hline \multirow{4}{*}{ 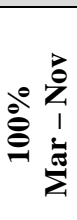 } & Mean ACH & 3.63 & 20.1 & 13.43 & 8.83 \\
\hline & Meets HTM's 6 ACH? & $\mathrm{No}$ & Yes & Yes & Yes \\
\hline & Mean flow rate (l/s/patient) & 69.9 & 387 & 258.6 & 170 \\
\hline & Meets WHO’s $60 \mathrm{l} / \mathrm{s} /$ patient? & Yes & Yes & Yes & Yes \\
\hline \multirow{4}{*}{ 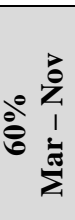 } & Mean ACH & 2.41 & 12.42 & 8.35 & 5.53 \\
\hline & Meets HTM's 6 ACH? & No & Yes & Yes & No \\
\hline & Mean flow rate (l/s/patient) & 46.3 & 239 & 160.8 & 106.4 \\
\hline & Meets WHO’s 60 l/s/patient? & No & Yes & Yes & Yes \\
\hline
\end{tabular}

Notably, the (as-built) window-based strategy of Case 1 is unable to meet any of the airflow rates required by HTM 03-01, WHO or EN ISO 7730, except when openings are at $100 \%$ between March and November. Conversely, the CBNV meets the required flow rates for all the standards except at $60 \%$ opening between March and November for HTM 03-01, but even then $5.53 \mathrm{ACH}$ is just marginally short of $6 \mathrm{ACH}$.

\subsection{Thermal comfort}

The performance of each strategy regarding thermal comfort was evaluated using predicted mean vote (PMV), predicted percentage dissatisfied (PPD) as well as dry resultant temperature, all of which were obtained from DTS results. PMV is rated using a scale (ranging from +3 to -3 ) in which: $+3=$ hot; +2 = warm; +1 = slightly warm; 0 = neutral; $-1=$ slightly cool; $-2=$ cool and $-3=$ cold [23]. The potential for overheating was appraised from CFD results using an assumption of $28^{\circ} \mathrm{C}$ outdoor temperature.

With a heat setpoint of $25^{\circ} \mathrm{C}$ in January, the PMV values (Fig 5a) are within acceptable range for all Cases with values generally around the ideal value of zero. This is with the exception of: Case 1 , where for substantial number of days, PMV values exceed 0.5 and approach 1.5 (i.e. between slightly warm and warm); and Case 4 where PMV approaches 0.5 for 5 days. These comfort readings are supported by the predicted percentage of people who would be dissatisfied with their thermal environment (Fig. 5b), where it is observed that Case 1 would have up to $60 \%$ dissatisfied occupants on specific days.

(Fig. 5 goes here - Full page width)

Figure 5: Opening fraction at $25 \%$ with $20^{\circ} \mathrm{C}$ setpoint for (a) PMV and (b) PPD

For comfort in summer, the PMV values (Fig. 6a) and PPD values (Fig. 6b) taken for the entire summer period (July to August) indicate that both $100 \%$ and $60 \%$ opening fractions produce different patterns of indoor comfort ranges. Again, for both opening fractions, Case 1 has more days when both 
Adamu, Z.A., Price, A.D.F and Cook, M.J. (2012) Performance evaluation of natural ventilation strategies for hospital wards - A case study of Great Ormond Street Hospital, Building and Environment, Vol. 56 pp. 211 - 222

PMV and PPD values exceed 1.0 (slightly warm); but with over 15 days when PMV is in the 1.5 and 2.0 range.

(Fig. 6 goes here - Full page width)

Figure 6: PMV comfort ranges at 100\% and 60\% openings for July to August

Figures 7, shows that during the non-winter months of March to November, the ventilation strategies would perform in terms of internal dry resultant temperatures ranges if openings were left at $100 \%$ (Fig. 7a) or when openings are constricted to $60 \%$ their original size (Fig. 7b). Noticeably, at $60 \%$ opening fraction, (Fig. 7b) Case 1 performs relatively poorly with just 42 days falling within $21-22^{\circ} \mathrm{C}$ range. Consequently this case also has the most days (91) when temperatures would exceed $28^{\circ} \mathrm{C}$ which is three times as many days when other cases experience $>28^{\circ} \mathrm{C}$ temperatures.

\section{(Fig. 7 goes here - Full page width)}

Figure 7: Indoor temperature ranges in non-winter months at (a) 100\% and (b) 60\% opening

At $100 \%$, Case 4 (CBNV) performs exceptionally better in keeping temperatures between 20 and $21^{\circ} \mathrm{C}$ during the non-winter months. This can be attributed to mixing behaviour previously observed for the NPV system in [12], as opposed to the displacement behaviour of the other three cases.

With regards to EN ISO 7730 standard [22], Fig. 8 is an indication of the percentage of hours where the given PMV ranges would be achieved in winter (Fig 8a) and other months (Fig. 8b).

(Fig. 8 goes here - Full page width)

Figure 8: Thermal comfort results using PMV for (a) winter months and (b) non-winter months

\subsubsection{Overheating potential}

The size and location of the single opening of Case 1 has been shown to cause discomfort in winter at $25 \%$ opening fraction. While this can is attributable to the low airflow rates in winter. During summer, when temperatures can exceed $28^{\circ} \mathrm{C}$, this ventilation strategy is also problematic. Firstly, airflow would be restricted due to entrainment of stale air with incoming fresh air, leading to conflict in airflow direction and hence reduction in flow rates (mean July flow rates are $65 \mathrm{l} / \mathrm{s}$ and $44.7 \mathrm{l} / \mathrm{s}$ at 100 and $60 \%$ fractions respectively). At $28^{\circ} \mathrm{C}$ in summer specifically, this conflict is evident from high indoor temperature as suggested by CFD contours in Fig. 9a. Also, the Age of air and 2D flow vectors from CFD results in Fig. 9b indicate that indoor air will be quite stale. Secondly, because already warm stale air which ought to exit the room is forced to mix with incoming fresh air, this leads to overall build-up of internal heat. This build-up of heat helps to explain the apparent low winter energy consumption of Case 1 which scored number 1 in the energy rankings. It is also observed from Fig. 9a that internal temperatures could rise to as high as $40^{\circ} \mathrm{C}$ (from top of window towards ceiling) when outdoor air is $28^{\circ} \mathrm{C}$, and the mean Age (Fig. 8b) of fresh air at lower portion of opening is $1874 \mathrm{~s}$ while Age of outgoing air is about 4000s. The mean temperature at the bed and sitting visitor's head in this Case is $\approx 38^{\circ} \mathrm{C}$, (Fig. 9a) a rise of $10^{\circ} \mathrm{C}$ above outdoor air temperatures. This is a plausible explanation of why over-heating does occur in summer when single openings are used in such spaces. The mean Age of air (Fig. 9b) at the bed level and visitor's head is also significantly high at $\approx 3008 \mathrm{~s}$, an indication of staleness of air at these locations. The rising plume of hot air over visitor approaches $40^{\circ} \mathrm{C}$. 
(Fig. 9 goes here - Full page width)

Figure 9: Summer CFD results for Case 1 showing (a) indoor temperature (b) Age and 2D flow vectors

For Case 2, where there is clear distinction in flow airflow paths (Fig. 10), the room temperature builds up when outdoor air is $28^{\circ} \mathrm{C}$ (Fig. 10a) is not as severe as in Case 1 . The maximum indoor temperature is $\approx 32^{\circ} \mathrm{C}$ towards the ceiling while the Age of air at outlet is $\approx 1254 \mathrm{~s}$, and almost 0 s at inlet (Fig. 10b). Also, it is noticed that mean temperature around bed level (and head of sitting visitor) is $\approx 30^{\circ} \mathrm{C}$, (a rise of $2^{\circ} \mathrm{C}$ above outdoor air temperature). This is also the mean temperature of rising plume of hot air over the visitor. Also, unlike Case 1, the mean Age at these occupant locations is $\approx$ 419s. The maximum room temperature in Case 2 is up to $8^{\circ} \mathrm{C}$ lower than what obtained in Case 1 , which emphasises the benefits of having segregated openings.

(Fig. 10 goes here - Full page width)

Figure 10: Summer CFD results for Case 2 showing (a) indoor temperature (b) Age and 2D flow vectors

In Case 3, the mean temperature at the bed level and at visitors head location (Fig. 11a) is $\approx 29^{\circ} \mathrm{C}$ representing a rise of just $1^{\circ} \mathrm{C}$ above outdoor air temperature at that location, ignoring the rising plume of hot air $\left(31^{\circ} \mathrm{C}\right)$ over visitor. The maximum room temperature is $32^{\circ} \mathrm{C}$ towards the ceiling. The Age of air is 0s at inlet (Fig. 11b) and about 29s at the bed level. These represent significant differences compared to Case 1 and 2.

(Fig. 11 goes here - Full page width)

Figure 11: Summer CFD results for Case 3 showing (a) indoor temperature (b) Age and 2D flow vectors

For Case 4, when outdoor air is $28^{\circ} \mathrm{C}$, the CBNV offers more uniformity in both the mean temperature and Age of air in the space. There is a distinct lack of rising plume of hot air over the visitor, suggesting better comfort than in other cases and maximum room temperature is about $32^{\circ} \mathrm{C}$. Like in Case 3, at the patient's bed level the temperature is also $\approx 29^{\circ} \mathrm{C}$ (Fig. 12a) i.e. $1^{\circ} \mathrm{C}$ above outdoor air temperature. The absence stratification of indoor air temperature or Age of air unlike previous cases and this can be attributed to the mixing of room air due to drop and subsequent rise of incoming cooler air as shown by 2D vectors in Fig. 12b. This mixing characteristics clearly has comfort benefits, and further (planned) studies should reveal how this affects dilution of airborne contaminants.

(Fig. 12 goes here - Full page width)

Figure 12: Summer CFD results for Case 4 showing (a) indoor temperature (b) Age and 2D flow vectors

Figure 13 shows the predicted flow behaviour of both CBNV ducts using temperature and 2D flow vectors at outdoor temperature of $19^{\circ} \mathrm{C}$. The mixing offered by both ducts is evident even though the slice planes are in two dimensions, however, from the pattern of vectors on the floor (z-axis) planes which indicate distribution of cooler air in all directions is evidence of mixing characteristics offered by CBNV. 
(Fig. 13 goes here - Single column width)

Figure 13: Airflow vectors through both CBNV ducts

\subsection{Heating load and energy consumption}

January was also used as a sample winter month in which $25 \%$ opening fraction of openings can be used to evaluate heating energy patterns and to estimate the total heating required for each case. Figure 13 describes the pattern of heating load using January as an exemplar winter month for all cases, where Fig. 13b suggests that Case 1 would have the least heating load, with required power peaking at $1.5 \mathrm{~kW}$. While this represents the lowest heating load of all four cases, this comes with a comfort penalty as evident from PMV values (Fig. 5a) which are high for about two-thirds of the month.

From Fig. 14, it can be seen that at the same (25\%) opening fraction in January, the heating load/power that would be imposed on the Cases differ (Fig. 14a). Case 2 in particular would experience the most heating load in January with values approaching $5 \mathrm{~kW}$, although this peak value would be for just four days, while for most other days, the load would fluctuate between 0.5 to $4.5 \mathrm{~kW}$ (Fig. 14b). Case 3 at 25\% opening fraction would result in up to 13 days where the space has to cope with between 1 and $2 \mathrm{~kW}$ of heating load (Fig. 14b) but a maximum load of $3.5 \mathrm{~kW}$ would be required for 1 day only. Finally, while the heating power in Case 4 would actually approach 2.5kW (for 1 day only) and this strategy would require up to 20 equivalent days of heating in January using $0.5 \mathrm{~kW}$ of power only (Fig. 14b).

\section{(Fig. 14 goes here - Full page width)}

Figure 14: Equivalent number of heating days (January)

Summarily, the cases were compared and ranked in terms of total monthly energy (in MWh) expected to be consumed for heating the entire winter months of December to January. Table 2 shows the results for each cases as well as their performance ranking.

Table 2: Performance ranking based on total energy (MWh) consumed in winter

(Table 2 Goes Here - Single column width)

The DTS modelling results can produce mean energy requirement from each strategy, which can become an input for CFD modelling of room heaters - and subsequently a potential source for customised sizing of room heating equipment. With $25 \%$ opening fraction in the month of January for instance, the mean heating requirements for all cases are shown in Table 3, when mean dry bulb temperature is $3.75^{\circ} \mathrm{C}$.

Table 3: Heating load at 25\% opening for January

(Table 3 Goes Here - Full page width)

For energy benchmarking of each Case, CIBSE's benchmark for hospitals i.e. Category 20 buildings [24] are used for evaluating performance of each strategy. Appendix 1 (Table 4) provides a summary of monthly energy consumed using $80 \%, 35 \%, 25 \%$ and $12.4 \%$ opening fractions, as well as the 
annual summations. From the given table, the poor energy performance of Case 2 which allows significant flow rates is obvious because it goes over CIBSE's $90 \mathrm{kWh} / \mathrm{m}^{2}$ benchmark [24] i.e. equivalent to $2.12 \mathrm{MWh}$ for the $23.55 \mathrm{~m}^{2}$ of ward space, even at $12.5 \%$ opening fraction. Only Case 1 and Case 4 fall below this benchmark at $12.5 \%$ and $25 \%$ opening fractions. Although, as discussed earlier, Case 1 (the as-built strategy which has a single opening) consumes significantly less energy even at $35 \%$ and $80 \%$ opening fractions, the CFD results show evidence of recirculation of outgoing air and hence re-heating of incoming fresh air indicating the consequent comfort penalties that will definitely ensue. Further work being planned on the impact of this recirculation on dispersal of airborne contaminants (and cross-infection) is expected to further shed light on the behaviour of this and other strategies.

A composite graph that combines different opening fractions and their consequent heating loads in attempt to normalise monthly consumptions is provided in Fig. 15. Added into monthly totals over a whole year, the energy consumed by each strategy would fall below the $90 \mathrm{kWh} / \mathrm{m}^{2}$ benchmark. As no single Case consumes up to or above this electricity benchmark monthly or annually, the case for fossil-thermal (i.e. $420 \mathrm{kWh} / \mathrm{m}^{2}$ ) was not considered for evaluation. From Appendix 1, the maximum to be consumed annually would be 32.753 MWh using $80 \%$ opening fraction in Case 2 .

(Fig. 15 goes here - One and half column width)

Figure 15: Monthly heating loads at different opening fractions

\subsection{Conclusions}

The performances of four architecturally distinct natural ventilation strategies were evaluated with respect to airflow capacity, thermal comfort and summer overheating as well as potential heating energy consumption in winter.

Strategies such as Case 2, Case 3 and Case 4 provide distinctly segregated flow paths for incoming and outgoing air (as shown previously by CFD Age of air and flow vector results). Although this segregation of flow openings is desirable for meeting high air change rates and dilution, it comes with energy penalties. Whereas the mean January airflow rates for Cases 2 and 3 are substantial at $152.8 \mathrm{l} / \mathrm{s}$ $(\approx 7.9 \mathrm{ACH})$ and $99.5 \mathrm{l} / \mathrm{s}(\approx 5.2 \mathrm{ACH})$ respectively; in terms of heating energy, Case 2 was ranked last (at number 4), while Case 3 was ranked second to last in Table 1 . Case 4 appears to be a good compromise among the cases due to its modest airflow (mean January flow is $64.3 \mathrm{l} / \mathrm{s}(\approx 3.3 \mathrm{ACH})$ and its position is number 2 in the energy ranking (Table 2). The performance of Case 4 (CBNV) in terms of comfort and energy is attributable to its mixing behaviour, achieved regardless of its relatively modest airflow rates. Such mixing characteristics of the CBNV have previously being the exclusive reserve of mechanised ventilation systems, so it is encouraging that a low-energy (buoyancy-driven) natural ventilation alternative is feasible. The distinct difference in airflow rates performance is summarised in Table 1 where Case 4 meets all the minimum requirements of HTM 0301, the WHO and EN ISO 7730; whereas Case 1 (window-based) fails to meet all, except for $6 \mathrm{ACH}$ (HTM 03-01) and that is only if openings are left at $100 \%$ between March and November. The significant variations in airflow rates demonstrated by these four distinct strategies point to need for ventilation standards to be more comprehensive in suggesting established design strategies which can achieve the prescribed flow rates, for the benefit of designers and facility managers. It is inadequate to specify air flow rates without suggesting how they might be achieved. Subsequently, there is need for developing performance-based natural ventilation codes, which would encourage further research into more creative ways of using natural ventilation (other than windows) for hospitals and similar buildings. 
Interestingly, HTM 03-01 (Section 2.6, pp 8) implies that single-sided natural ventilation is effective only to a depth of $3 \mathrm{~m}$. However, the as-built reality of the new Great Ormond Street Hospital ward is that it utilises this strategy (i.e. the $1.9 \mathrm{~m}$ high window) in its single-bed wards which was modelled as Case 1 in this study. The creation of a lower inlet (i.e. converting it to same side dual-opening as in Case 2) will result in significant improvements in airflow rates. This would be a relatively cheaper and easier option than inlet and stack or CBNV, should refurbishment be considered for this or similar facilities. In fact, the airflow potentials of Case 2 is limited only by its significant winter energy demands, which can be countered with appropriate sizing and control mechanisms; or with heat recovery via bathroom exhausting. However, the WHO on the other hand, does not encourage the use of dual-openings for airborne contaminant control in multi-floor facilities due to dangers of cross flow from outlets of lower floor to inlets of higher floors [20]. But for facilities whose wards are not multifloor, dual-openings remains a viable option especially for retrofitting purposes. It is probably secondbest option to cross-ventilation in terms of airflow, but most modern facilities especially in urban locations are unable to have openings on two separate walls due to architectural and/or operational constraints.

The patterns and direction of airflow shown by CFD results indicate that alternative strategies (Cases 2, 3 and 4) are indeed better in many regards than Case 1 . These results collectively help to explain the poor performance of single window openings when used for natural ventilation. Additionally, the DTS results have shown potential to assist designers in evidence-based sizing of heating equipment using mean monthly energy consumption, for whatever ventilation strategy is chosen. This approach has benefits especially at the schematic design stage when far reaching decisions are made about building configuration.

In general, the methods used in sizing openings were based on an empirical model in Case 2 and a rule of thumb in Case 3 and Case 4, however, while using the rule of thumb (percentage of floor area) has been tested and validated in previous studies of ANV systems similar to Case 3 [4, 15]; using the same sizing technique for the CBNV is probably inappropriate. Apart from similarity in exhaust stacks, Case 4 differs significantly because the CBNV functions with elevated and horizontal supply ducts and a neutral pressure line which is reduced by the elevated ducts. A technique for determining the appropriate size of ducts is therefore required and is under consideration. This is possible, for example by using trial and error to systematically increasing the percentage of floor area from current $1.5 \%$ upwards until a size which delivers equivalent flow rate as Case 3 is achieved. The mixing property of Case 4 is a feature that has hitherto been the exclusive reserve of mechanical ventilation. This mixing is evidently pronounced by falling and rising of CFD airflow vectors, through the absence of temperature strata (common in displacement ventilation); as well as through the minimisation of rising plume of hot air over occupants. This mixing characteristic can be exploited further as it has obvious thermal comfort benefits, which manifests in more uniform room temperature. Expectedly, this has contributed to the low heating energy required in Case 4.

Case 2 (same side dual-openings) produced the highest flow rates, leading to substantial heating energy requirements as well as potential for draught at the floor level, but these can be overcome by better automation and control of openings. The tool used for the dynamic simulation is unfortunately limited in not allowing airflow rates to be used as regulating sensors. Using $\mathrm{CO}_{2}$ as an indicator for acceptable indoor air quality by such applications is a weakness because high airflow rates can be required in clinical environments for health and safety reasons, regardless of the presence of occupants. It should also be pointed out that although Case 3 (inlet and stack) produces mean flows of 5.2 ACH in winter (January), this is arguably an over-ventilation with significant heating required to achieve acceptable thermal comfort.

In summer, the CBNV of Case 4 produces mean flows of $132 \mathrm{l} / \mathrm{s}(6.9 \mathrm{ACH})$ and $87.4 \mathrm{l} / \mathrm{s}(4.5 \mathrm{ACH})$ at $100 \%$ and $60 \%$ opening fractions respectively. This flow rates may appear acceptable, using the 6ACH benchmark of HTM 03-01 [13] but it has been argued severally [14, 15]; and inferred from a 
specific enquiry made directly to ASHRAE [30] that this benchmark rate is rather ambiguous in origin, even if it enjoys an apparent consensus amongst researchers and practitioners. Additionally, the absolute (and personalised) flow rates of $60 \mathrm{l} / \mathrm{s} /$ patient recommended by the WHO could be a better metric if the rates per patient can be scientifically justified. This is because since it ties ventilation to occupancy (patients) and not room volume (ACH) therein lies the potential for NPV [12] and CBNV systems. Both concepts can induce the movement of fresh outdoor air towards each patient as defined by Melikov [21] for personalised ventilation - but using buoyancy only, thus at zero energy (or low energy, if fans are to provide occasional assistance).

The CBNV is uniquely unable to produce any flow for 222 hours of the year, (i.e. about 9 days) between July and August. This is probably due to its incapacity to cope with weak temperature differentials between interior and exterior, further emphasising the need to standardise its component sizing methods. This also makes a case for hybrid modes in certain times of the year when fanassistance at either the supply duct or exhaust stack is necessary to enhance airflow. Although Case 1 (window-base) was computed to produce zero flows as well for 1721 hours (71 days) in the same summer months, this is not attributable to weak temperature differentials only. The use of a single opening (for inflow and outflow of air) leading to conflict in flow directions or entrainment is the most plausible explanation as suggested by CFD results (Fig. 8). Importantly, the use of distinct inlets and outlets in natural ventilation (as represented by Case 2, 3 and 4) clearly has potential to minimise overheating which as occurs in Case 1 can be for up to three months.

\subsection{Future work}

Further to this work, there is a need to explore how the mean monthly DTS energy loads can aid the sizing of room heaters which can be studied in detailed through CFD models. However, locating such heaters requires careful consideration as their positions can affect comfort and efficiency of heating and it may emerge from further CFD studies that optimum placement could lead to even better comfort and lower energy than suggested by DTS simulations. It is also possible to monetise the equivalent consumption of energy from both electricity and gas sources under each strategy as this can aid designers and clients in making informed decisions about cost implications of proposed design alternatives. However, as evident from this study, savings in energy need to be cross-referenced with equivalent performance in delivering adequate airflow rates and acceptable thermal comfort. The CBNV in particular presents a unique challenge in the design and location of heating system at the fresh air supply points, without which cold drafts over occupants are almost a certainty. The performance of CBNV is currently being validated through salt-bath experiments of the NPV Case 1 and Case 2 duct configurations, previously demonstrated [12] in Adamu et al. (2011). Such experiments have the potential to offer visualisation of transient flow across the NPV duct as well as understanding the real-time nature of mixing which occurs within the ventilated space. There is also a need to model the performance of heat-recovery ventilator fitted within the bathroom from where unwanted air is channelled first before being exhausted e.g. through the stacks.

Finally, there is also a need to assess the performance of these four selected strategies with respect to control of infectious bio-aerosols in same or similar ward spaces. This aspect was not considered in the present study due to several reasons. First, there is need for focus and for the systematic classification of findings according to airflow rates, energy and comfort. Second, the control of bioaerosols is a unique subject of special interest in its own right given contemporary concerns about airborne pandemics in hospitals (e.g. SARS, H1N1) as well as drug-resistant strains of diseases like Methicillin-resistant Staphylococcus aureus (MRSA) and Tuberculosis (DRTB). Third, because the potential source of airborne pathogens can vary: from a sitting visitor (position 'b' in Fig. 1); to a sleeping visitor (position ' $c$ ' in Fig. 1); or even a standing healthcare worker (who is often mobile). These three locations represent extensive variability of pollutant source which require a dedicated study. Concurrent (and independent) research is therefore exploring these issues. 
With reference to the findings from this study, it is expected that in future work, weights could be assigned to each of four major parameters (airflow, thermal comfort, energy and bio-aersosol control) so that the performance of each ventilation strategy can be translated into alternative solutions, whereby designers, facility operators and infection control experts can elect or rank the aspect of ventilation that matters most to the client or clinical space in question. That way, objective selection of a ventilation strategy can not only be done -based on evidence, but can also be explained especially if the quantitative and qualitative metrics are encoded into an expert system.

\section{Acknowledgements}

The authors are grateful to: Engineering and Physical Sciences Research Council (EPSRC) of the UK; the Innovative Manufacturing Research Centre (IMRC); the Health and Care Infrastructure Research and Innovation Centre (HaCIRIC) as well as Llewelyn Davies Yeang Architects and the Department of Health/Great Ormond Street Hospital (GOSH) for supporting this research.

\section{References}

1. Qian H, Li Y, Seto WH, Ching P, Ching WH, Sun HQ. Natural Ventilation for reducing airborne infection in hospital: Building and Environment, 2010; 45: 559-565

2. Lomas, KJ and Giridharan R. (2011) Thermal comfort standards, measured internal temperatures and thermal resilience to climate change of free-running buildings: a case-study of hospital wards, Building and Environment, Available online (22 Dec. 2011) at: http://dx.doi.org/10.1016/j.buildenv.2011.12.006,

3. Short CA, and Al-Maiyah S. Design strategy for low-energy ventilation and cooling of hospitals, Building Research \& Information, 2009; 37(3): 264-292

4. Lomas, KJ. Architectural design of an advanced naturally ventilated building form. Energy and Buildings, 2007; 39:166 - 181.

5. Khanal R, and Lei C. Solar chimney - A passive strategy for natural ventilation, Energy and Buildings, 2011; 43(8): 1811-1819

6. NHS, Quality and Performance, Report to Trust Board, University Hospitals of Leicester, Trust Board report, 2010; 47.

7. Allocca C, Chen Q. and Glicksman LR. Design analysis of single-sided natural ventilation. Energy and Buildings, 2003; 35: 785-795

8. Beggs CB, Kerr KG, Noakes CJ, Hathway EA and Sleigh PA. The ventilation of multiple-bed hospital wards: Review and analysis. American Journal of Infection Control, 2008: 36(4): 250-259.

9. Li Y, Nielsen PV and Sandberg M. Displacement Ventilation in Hospital Environments, Ashrae Journal, 2011; 53(6): 86-88.

10. Adamu ZA, Cook MJ, Price ADF. Natural Personalised Ventilation: A novel approach, International Journal of Ventilation. 2011; 10(3): 263-275.

11. Chen Q. Ventilation performance prediction for buildings: A method overview and recent applications, Building and Environment, 2009: 44(4): 848-858

12. Li Y and Nielsen P V. CFD and ventilation research, Indoor Air, 2011; 21(6): 442-453

13. DoH, Department of Health: Heating and ventilation systems; Health Technical Memorandum 0301: Specialised ventilation for healthcare premises. TSO (The Stationery Office); 2007. Also available at www.tsoshop.co.uk. Accessed Feb. 2011.

14. Gammage, RB. Controlling aerial transmission of Aspergillosis, Legionellosis and Drug-Resistant Tuberculosis. In Maroni M, editor. Ventilation and Indoor Air Quality in Hospitals. Dordrecht: Kluwer Academic Publishers, 1996: 71-84.

15. Lomas KJ, Ji Y. Resilience of naturally ventilated buildings to climate change: Advanced natural ventilation and hospital wards, 2009 Energy and Buildings; 41: 629-653 
16. Atkinson J, Chartier Y, Pessoa-Silva CL, Jensen P, Li Y and Seto W-H, editors. Natural Ventilation for Infection Control in Health-Care Settings. WHO Guideline. 2009, WX 167.

17. Li Y, Leung MKH, Seto WH, Yeun PL, Leung J, Kwan JK, et al. Factors Affecting Ventilation Effectiveness in SARS wards. Hong Kong Medical Journal. 2008; 14: 33-6.

18. DoH (2006): Health Technical Memorandum 07-02: EnCO2de-, Making Energy Work in Healthcare, Environment and Sustainability, Department of Health Estates and Facilities Division, The Stationary Office, ISBN: 0-11-322731-0.

19. CIBSE. Natural ventilation in non-domestic buildings, CIBSE Applications Manual AM10. Second Edition, 2005, Chartered Institution of Building Services Engineers Publications, ISBN 1903287561.

20. Awbi HB. Ventilation of Buildings. Second Edition, 2003, ISBN 0415270553, Abingdon: Taylor and Francis (E\&FN Spon).

21. Melikov A. Personalized ventilation. Indoor Air, 2004; 14:157-167

22. Olesen BW. The philosophy behind EN 15251: Indoor environmental criteria for design and calculation of energy performance of buildings. Energy and Buildings. 2007; 39:740-9

23. ISO. Moderate thermal environments: Determination of the PMV and PPD indices and specification of the conditions for thermal comfort, ISO 7730, 1994-12-15.

24. CIBSE. Energy Benchmarks, Technical Memorandum 46, 2008: ISBN 9781903287958

25. CIBSE. Guide A: Environmental Design, The Chartered Institution of Building Services Engineers, 2006: London.

26. Koestel A. Paths of horizontally projected heated and chilled air jets. Trans. ASHAF, 1955; 61:231-2.

27. IES. Integrated Environment Solutions, IES VE Software Version 6.2.0.3, 2011; www.iesve.com

28. Cham. Phoenics version 2009, available from: Cham Co. Ltd. http://www.cham.co.uk/.

29. Yakhot V, and Orszag SA. Renormalization group analysis of turbulence. Journal of Scientific Computing 1986; 1: 3-51.

30. Hammerling, S., shammerling@ashrae.org. Subject: ASHRAE/ASHE 170-2008. [Email] Message to Z.A.Adamu@lboro.ac.uk. Personal communication; Sent Tuesday, 3rd November 2009, 20:00; (Steve Hammerling, Assistant Manager of Research \& Technical Services, ASHRAE, USA). 
Adamu, Z.A., Price, A.D.F and Cook, M.J. (2012) Performance evaluation of natural ventilation strategies for hospital wards - A case study of Great Ormond Street Hospital, Building and Environment, Vol. 56 pp. 211 - 222

\section{Appendix 1}

Table 4: Monthly and annual heating plant sensible load (MWh) for selected opening fractions

(Table 1 Goes Here - Full Page Landscape width) 